\title{
Preparation and Characterization of Thermoplastic Elastomers/Plasticizer - Compatibilizer/Organoclay Nanocomposites by Reactive Extrusion System
}

\author{
Mostafa ASGHARI DILMANI ${ }^{1 *}$, Zakir MOR $^{1}$ and Erdoğan A $^{2}$
}

${ }^{1}$ Division of Nanotechnology and Nanomedicine, Institute of Science and Engineering, Hacettepe University, Beytepe, Turkey

${ }^{2}$ Department of Chemical Engineering, Faculty of Engineering, Hacettepe University, Beytepe, Turkey

\begin{abstract}
Polymer layered silicate nano-composites were prepared in melt by reactive extrusion $(25: 121 \mathrm{~mm}$ Rondol twinscrew compounding line) using poly(ethylene-co-propylene- co-ethylidenenorbornene) terpolymer (EPDM) as a matrx polymer, PP-g-MA and poly[(maleic anhydride-alt-1-octadecene)-g-PEO (poly(MA-alt-OD)-g-PEO) as functionalized polymer compatibilizer-internal plasticizer, octadecyl amine-montmorillonite (ODA-MMT) and dimethyldidodecyl ammonium -MMT (DMDA-MMT) as reactive and non-reactive nano-fillers, respectively. The formation of nano structural fragments, polymer blend composition-properties (thermal behavior and morphology) was studied using FTIR, XRD, TGA-DTG and DSC analysis methods. It was found that intercalation/exfoliation degree of EPDM macromolecules significantly depends on the origin and content of organoclays. Better results were obtained for nanocomposites prepared in the presence of reactive organo-filler (ODA-MMT) and PEO grafted alternating copolymer. The results of FTIR (chemical structure) and XRD (physical structure and exfoliation degree) analyses indicate that amidization of anhydride copolymer with alkyl amine groups of organo-filler and esterification of alternating copolymer with $\alpha$ -hydroxy- $\omega$-methoxy- PEO occur in melt compounding in situ processing in the chosen extrusion conditions (barrel temperature: $120,130,140$ and $145^{\circ} \mathrm{C}$, twin-screw speed around $\left.30-40 \mathrm{mrp}\right)$. The glass-transition $(\mathrm{Tg})$, melting (Tm) and recrystallization (Tc) temperatures strongly depend on the origin and content of organoclay and PEO-grafted copolymer-compatibilizer, respectively. Thermal behavior, crystallinity and thermostability of nanocomposites were significantly improved as compared with pristine EPDM terpolymer.
\end{abstract}

Keywords: EPDM rubber; PP-g-MA; Alternating copolymer; PEO; Organoclays; Reactive extrusion; Nanocomposites

\section{Introduction}

In the last decade, an increasing number of research groups in academia and industry focused their research efforts on thermoplastic and thermoset polymer, synthetic and natural rubber silicate layered (PLS), polymer/silica hybrid (PSH) and polymer/carbon nanotube (PCNT) nanocomposites. This considerable scientific and engineering interest has been stimulated by the possibility of the significant improvements in physical, mechanical, thermal and other important specific properties of PLS materials. The results of these studies, especially on PLS were summarized and discussed in several reviews [1-4] and books [5-8].

PLSs are a class of organic-inorganic hydride, composed of organic polymer matrix in which layered silicate particles of nanoscale dimension are embedded because these nanocomposites show enhanced mechanical properties [9-12], fine dispersed morphology [13], thermal stability [5,14], gas barrier properties [15-18], and improved chemical resistance [19] low flammability [3,20-22] and protection effects from corrosion [18,23]. Many industrial applications have emerged since the discovery of organo-silicates. Particularly, the ability of organo- clays to swell and delaminate in organic solvents has led to their widespread use as rheological control agents, as additives in paints, greases, inks, and oil-well drilling fluids, as reinforcement/ filler in plastics and rubber, and as additives to enhance flammability of plastics [7].

Now organoclays, especially organo-montmorillonite (MMT) are the most widely utilizated silicates in polymer nanotechnology. MMT is a layered silicate, crystal lattice which consists of two silica tetrahedral and one aluminum octahedral sheets with a plate-like structure of 1-nm thickness and 100-nm length [24]. Isomorphous substitution of central metal ion $\mathrm{Al}^{3+}$ by lower-valent metal ions, i.e., $\mathrm{Mg}^{2+}, \mathrm{Mn}^{2+}$, results in a charge imbalance of the surface of each platelet. The negative charge imbalance is neutralized by the absorption of hydratable cations, i.e., $\mathrm{Na}^{+}, \mathrm{Ca}^{2+}$, being responsible for the hydrophilic nature of MMT [8] MMT has hydrophilic surface with exchangeable metal ions and does not disperse very well in organic polymers, especially in hydrophobic polymers such as polyolefins, polystyrene, halogen-containing polymers, etc.

Recently, attention of many researchers has been focused on natural and synthetic rubber/organoclayclay nanocomposites due to their high mechanical and gas barrier properties and flame resistance. Many important properties of rubber/clay nanocomposites strongly depend on the dispersion state of organoclay in the rubber matrix. The interlayer spacing and dispersion of the organo-MMT are greatly affected by polar forces between the organoclay and the polymeric matrix material. The layered silicates dispersed at the nanosized level are reported to provide an effective reinforcement to synthetic and natural rubber materials [25-27]. There are very important studies

*Corresponding author: Mostafa AD, Division of Nanotechnology and Nanomedicine, Institute of Science and Engineering, Hacettepe University, Beytete, Turkey, Tel: +903124444444; E-mail: cavusogluilayda@gmail.com

Received July 13, 2017; Accepted July 20, 2017; Published September 13, 2017

Citation: Mostafa AD, Zakir MOR, Erdoğan A (2017) Preparation and Characterization of Thermoplastic Elastomers/Plasticizer - Compatibilizer/ Organoclay Nanocomposites by Reactive Extrusion System. Chem Sci J 8: 166 doi: $10.4172 / 2150-3494.1000166$

Copyright: (C) 2017 Mostafa AD, et al. This is an open-access article distributed under the terms of the Creative Commons Attribution License, which permits unrestricted use, distribution, and reproduction in any medium, provided the original author and source are credited. 
Citation: Mostafa AD, Zakir MOR, Erdoğan A (2017) Preparation and Characterization of Thermoplastic Elastomers/Plasticizer - Compatibilizer/ Organoclay Nanocomposites by Reactive Extrusion System. Chem Sci J 8: 166. doi: 10.4172/2150-3494.1000166

on the preparation and properties of rubber/clay nanocomposites, especially by means of a conventional rubber compounding process. EPDM and its MA grafted derivative were often utilized in preparation of nanocomposites by a melt compounding process. To control the dispersion of the organoclay in polymer blends different reactive copolymers- compatibilizers can be utilized in the blending process, which can significantly influenced the in situ exfoliation and dispersion processing, and therefore, the morphology and mechanical properties of nanocomposites. However, utilization in rubber/organoclay system functional copolymers as reactive compatibilizers is limited with functionalized graft copolymers, predominantly maleic anhydride grafted polyolefins or rubbers.

\section{Recent progress in rubber-organoclay nanocomposites}

The layered silicates dispersed at the nanosized level are reported to provide an effective reinforcement to synthetic and natural rubber materials [28-31]. There are very important studies on the preparation and properties of rubber/clay nanocomposites, especially by means of a conventional rubber compounding process. Wang et al. [29] prepared three kinds of rubber/clay nanocomposites by latex and solution methods. They showed that clay could be dispersed in the rubber matrix as one or several layers, while polymer molecules intercalated to the clay galleries; compared with other methods, the latex method was more convenient and could be widely used to prepare polymerclay nanocomposites. The authors reinforced the nanocomposites and other rubbers with carbon black and then processed with conventional technology, vulcanized, and tested. Rubber-clay nanocomposites were characterized with TEM and XRD. The TEM showed clay had been dispersed to one or several layers. The XRD showed that the basal spacing in the clay was increased. The clay layer could be uniformly dispersed in the rubber matrix on the nanometer level. The mechanical tests showed that the nanocomposites had good mechanical properties. Authors also reported the synthesis and properties of silicone rubber/ organo- montmorillonite hybrid nanocomposites prepared via a melt-intercalation process [30]. The resulting hybrid nanocomposites were characterized by X-ray diffraction (XRD), transmission electron microscopy (TEM), and thermogravimetric analysis (TGA). The results proved that the organo-montmorillonite could be exfoliated into ca. $50-\mathrm{nm}$ thickness and uniformly dispersed in the silicone rubber matrix during the melt-intercalation process. Furthermore, the mechanical properties and thermal stability of the hybrids were very close to those of aerosilica-filled silicone rubber. According to the authors, polyurethane nanocomposites form by adding a methylenebis- $p$ phenylene diisocyanate prepolymer to a mixture of organoclay and glycerol propoxylate, stirring at $50^{\circ} \mathrm{C}$ for $12 \mathrm{~h}$. The mixture was cured at $95^{\circ} \mathrm{C}$ for $10 \mathrm{~h}$ under $\mathrm{N}_{2}$ atmosphere; the alkylammonium exchange ions of the organoclay are assumed to couple to isocyanate groups. Gallery expansion beyond polyol solvation was evidenced by the authors using a broad X- ray diffraction peak at low angle, signifying that intragallery polymerization contributes to the dispersion of nanolayers. They found that the clay nanolayers, even when aggregated in the form of intercalated tactoids, strengthen, stiffen, and toughen the matrix; at a loading of only $10 \%$ organoclay whereas the strength, modulus, and strain -at- break increased by more than $100 \%$. According to the authors, the polyurethane-silicate intercalate nanolayer composites have good transparency, reduced water permeability, solvent resistance, making them suitable as packaging materials, protective films, and high barrier sealants.

E-P rubber-clay nanocomposites were prepared by meltcompounding poly[(E-P)-g-MA] with organophilic clay, and their properties were examined by Nasegawa et al. [32]. They found that silicate layers of the used clay exfoliated and homogeneously dispersed in the nanocomposites, which was confirmed by transmission electron microscopy observation. It is thought that MA units (or maleic acid groups generated by hydrolysis) grafted to the E-P polymer chains selectively absorb to the dispersed silicate layers and form strong ionic interaction, because MA units have good affinity to ionic surfaces of silicate layers. According to the authors, the silicate layers, dispersing at the nanometer level, play a role of large pseudo-crosslink points and improve creep resistance of nanocomposites. Nonocomposite technology using small amounts of silicate layers can lead to improved properties of thermoplastic elastomers with or without conventional fillers such as carbon black, talc, etc.

Ethylene -propylene- diene terpolymer (EPDM) is an unsaturated polyolefin rubber with wide applications. However, up to now, there have been very few investigations on grafting of MA onto EPDM in the molten phase and its further utilization in thermoplastics [3337], as well as on formation of EPDM/organoclay nanocomposites [38-41]. Uzuki et al. [38] prepared the hybrid nanocomposites based on organophilic montmorillonite (MMT) and ethylene-propylene -diene rubber (EPDM) by a melt compounding process. From the analysis by X-ray diffraction and transmission electron microscopy, authors found that the rubber molecules are intercalated into the galleries of organoMMT and the silicate layers of organoMMT are uniformly dispersed as platelets of 50-80 nm thickness in the EPDM matrix. Dynamic mechanical studies of authors indicate a strong rubber-filler interaction in the hybrid nanocomposite which is manifested in the lowering of $\tan \delta$ at the glass transition temperature. They demonstrated that the hybrid nanocomposites exhibit great improvement in tensile and tear strength, and modulus and elongationat-break as well as in barrier properties. According to Chang et al. [37], EPDM/organophilic montmorillonite hybrid nanocomposites could successfully be prepared by a simple melt compounding process. The organoclay prepared by treating sodium montmorillonite with the octadecylammonium ion and subsequently with a low molecular weight EPDM oligomer. X-ray diffraction analysis indicates that matrix rubber molecules could be intercalated into the gallery of the organoclay effectively. Moreover TEM images confirmed that silicate layers of the organoclay are uniformly dispersed on the nanometer scale in the EPDM rubber matrix. The uniform dispersal of the clay nanolayers in the rubber matrix is considered to form a physical barrier against a growing crack, which leads to the increase in the resistance to tearing. These observations of authors indicated that the intercalation of rubber macromolecules into the galleries of organo- MMT can offer the hybrid nanocomposite effective enhancement in toughness, strength and stiffness. In the EPDM hybrid filled with 10 phr of organo-MMT [dodecylammonium cation $\left(\mathrm{C}_{18} \mathrm{H}_{37} \mathrm{NH}_{3}^{+}\right)$modified montmorillonite], the oxygen permeability was decreased to $60 \%$ relative to unifilled EPDM. This unique barrier property was explained by the authors in forming dispersion of the impermeable clay with planar orientation in the rubber matrix, as observed by TEM micrographs.

Lee and Goettler [38] prepared the polymer blend nanocomposites, comprising nanoscale platelets derived from layered silicates treated with an organic modifier in thermoplastic vulcanizates (TPV) and polypropylene/EPDM blend, by direct melt intercalation. Authors showed that the interlayer spacing and dispersion of the organoMMT are greatly affected by polar forces between the nanoclay and the polymeric matrix material. The structure- property relationship studies of authors in this class of nanocomposites indicate that with the increase of organoclay loading, the tensile modulus of TPV/clay 
Citation: Mostafa AD, Zakir MOR, Erdoğan A (2017) Preparation and Characterization of Thermoplastic Elastomers/Plasticizer - Compatibilizer/ Organoclay Nanocomposites by Reactive Extrusion System. Chem Sci J 8: 166. doi: 10.4172/2150-3494.1000166

nanocomposites increases by up to $170 \%$ at $8 \mathrm{wt} \%$ organoclay loading, while tensile strength gradually decreases with increase of organoclay loading. According to the authors, it is possible to control the dispersion of the nanoclay in physical polymer blends using different addition sequences in the blending process, which can significantly affect the phase partitioning and mechanical properties.

Recently, Ahmadi et al. [39] pepared EPDM/clay nanocomposites with organoclay that was intercalated with MA grafted EPDM (MAg-EPDM) and EPDM-clay composites with pristine clay via indirect melt intercalation method. Authors characterized the dispersion of the silicate layers in the EPDM matrix by XRD and TEM analysis methods. They showed that the particles of organoclay were completely exfoliated in EPDM matrix, and the mechanical, thermal and chemical properties of nanocomposites were significantly improved compared with conventional composites. Yang et al. [40] reported two processing methods for one-step processing method, in which the elastomer and the filler directly melt blended with PP matrix, and the preparation of $\mathrm{PP} / \mathrm{EPDM}) \mathrm{SiO}_{2}$ ternary composites:

- One-step processing method, in which the elastomer and the filler directly melt blended with PP matrix, and

- Two-step processing method, in which the elastomer and the filler were mixed first, and then melt, was blended with pure PP. To control the interfacial interaction among the components, authors used two kinds of PP (virgin PP and grafted with MA, PP-g-MA) and $\mathrm{SiO}_{2}$ (treated with or without coupling agent). They found that the formation of filler-network structure could be a key for a simultaneous enhancement of toughness and modulus of PP and its formation seemed to be dependent on the work of adhesion and processing method. It was observed that the formation of filler-network structure was favorable in the two-step processing. According to the authors, in this case, a super toughened PP ternary composite with the Izod impact strength 2-3 times higher than PP/EPDM binary blend and 15-20 times higher than pure PP could be achieved.

Poly(ethylene-co-octene) (PEO) as a relatively new PO elastomer was manufactured by Dow Chemical Co. using a metallocene catalyst. It is known that PEO and PEO-g-MA form homogenous and fine dispersion blend with PP [41-45] and PA/thermoplastic polyurethane (TPU), respectively [46]. Chiu and Chuang reported that the $80 \mathrm{PA} / 20 \mathrm{TPU} / 20 \mathrm{POE}-\mathrm{g}$-MA blend prepared by twin screw extrusion has better tensile stress and elongation than non-modified 80PA/20TPU blend, and furthermore, PEO- $g$-MA significantly improves the impact strength of PA, even to super-toughness grade [47]. Wahit et al. used PEO as an effective toughening agent for preparation of rubber-toughened PP/PA6 nanocomposites [48-51]. They showed that the addition of PEO to the PA6/PP (PA6 (30/70) nanocomposites increased the toughness of the nanocomposites but with limited success due to its immiscibility with PA6. Recenty, these authors prepared PEO elastomer and PEO grafted MA (POE-g-MA) toughened nanocomposites of PP/PA6 containing $4 \mathrm{wt} \%$ organophilic modified MMT clay by melt compounding followed by injection moulding. PP-g-MA was used by authors to compatibilize the blend system [51]. According to the authors, elastomer domains of PEO-gMA show a finer and more uniform dispersion than that of $\mathrm{PEO}$ in the PP/PA6/organoclay matrix. They proposed that reduction in dispersed particle size and an increase in adhesion between the phases due to the reaction between the amino group of PA6 and the anhydride group of PEO-g-MA during melt compounding and formation of PEO-g-PA6 copolymer are important factors for the toughness and morphology improvement of these blends.
Natural rubber (NR) is widely used in various applications particularly for tires because of its excellent elastic properties over other synthetic counterparts. However, its non-polar character limits its application due to poor oil resistance and high air permeability [52]. Grafting of MA or other polar monomers onto NR backbone improves the compatibility between NR and other polar elastomers and some engineering plastics such as polyamide. According to several authors [53-59], the grafting process of MA onto polydienes, such as NR, styrene-isoprene, and styrene- butadiene-styrene block copolymer, involves two different mechanisms, i.e., radical-induced grafting and thermal grafting via an ene mechanism. For the ene mechanism, high temperature $\left(160-240^{\circ} \mathrm{C}\right)$ is required for the fixation of MA to polydiene backbone. In the case of radical mechanism, the reaction usually occurs quickly and at a lower temperature than the ene reaction [56]. The MA modification of different kinds of rubbers is a useful way of compatibilizing immiscible polymer blends as well as improving interfacial adhesion in polymeric composites. Thus, the modification of EPDM rubber with MA in a twin screw extrusion process has been described by Oostenbrink and Gaymans [60]. They proposed that the knowledge of MA content in the rubber by covalent linking is important not only to evaluate its application but also to choose the best manner of grafting. Couitinho et al. [61]. Chemically modified the EPDM elastomer (1.7\% of norbornene unit) with MA in chlorobenzene solution with benzoyl peroxide as an initiator. The presence of MA grafting on elastomer was determined by MR-FTIR analysis using 1856 and $1780 \mathrm{~cm}^{-1}$ band of anhydride carbonyl groups. The above mentioned, developed rubber functionalization methods via introducing polar units, especially MA will also definitely help in the utilization of these graft copolymers for the preparation of various polymer silicate layered nanocomposites with fine dispersion mineral clay, organoclay and silica particles [62-66] 1-origin,13,17,18,23]. Hakim and Ismail [62] prepared natural rubber (NR)/organoclay nanocom- posites by using maleated NR. They investigated the effect of organoclay content on the curing characteristics, mechanical and thermal properties and morphology of NR based nanocomposites. It was shown that organoclay filled NR nanocomposites with maleated NR exhibit shorter processing time, higher tensile properties and homogeneous dispersed morphology.

In this work, we firstly used dual compatibilizers such as poly(MA-alt-OD)/PP-g-MA and poly(MA-alt-OD)-g- PEO/PP-gMA in the EPDM/organoclays (reactive and non-reactive) systems. General schemes of proposed in situ physical and chemical interfacial interaction during the melt compounding processes can be represented as follows (Figures 1-3).

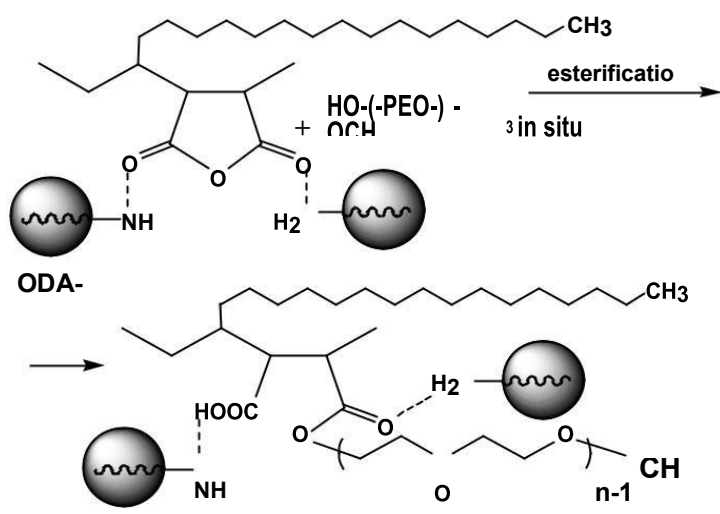

Figure 1: Esterification (grafting) in situ reaction during melt compouding of EPDM/PP-g-MA/Poly(MA-alt-OD)/ODA-MMT blend. 
Citation: Mostafa AD, Zakir MOR, Erdoğan A (2017) Preparation and Characterization of Thermoplastic Elastomers/Plasticizer - Compatibilizer/ Organoclay Nanocomposites by Reactive Extrusion System. Chem Sci J 8: 166. doi: 10.4172/2150-3494.1000166

Page 4 of 12

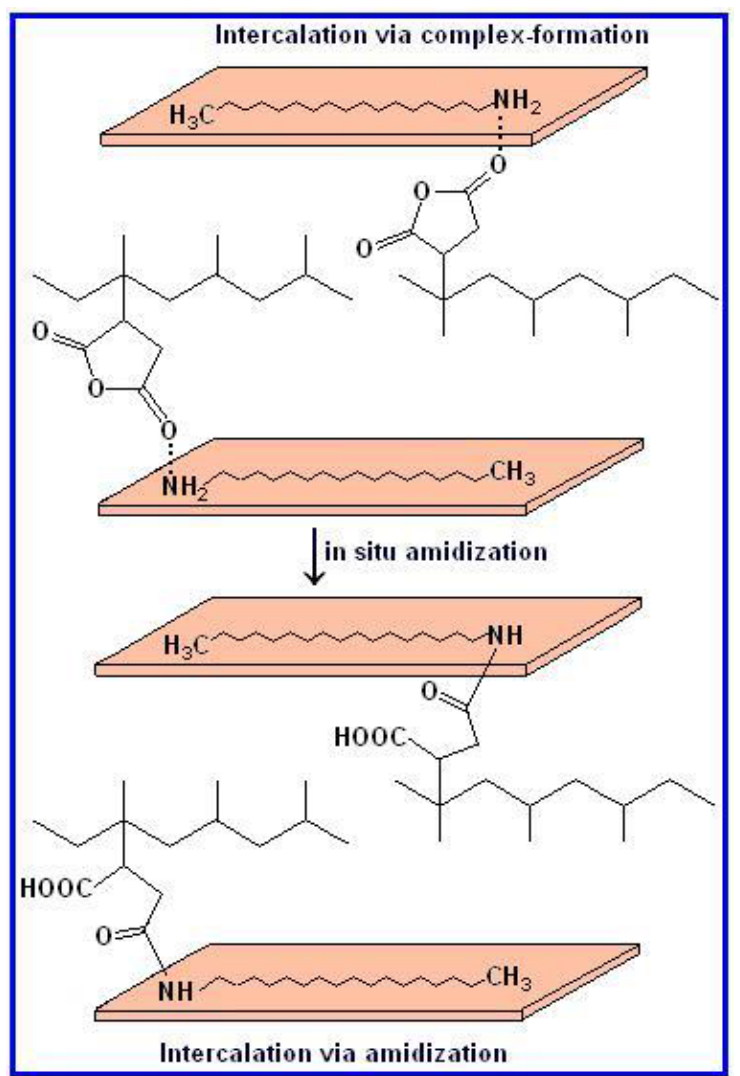

Figure 2: Physical and chemical interactions in situ processing during melt compounding of EPDM/PP-g-MA and/or poly(MA-alt-OD)/ODA-MMT blend.

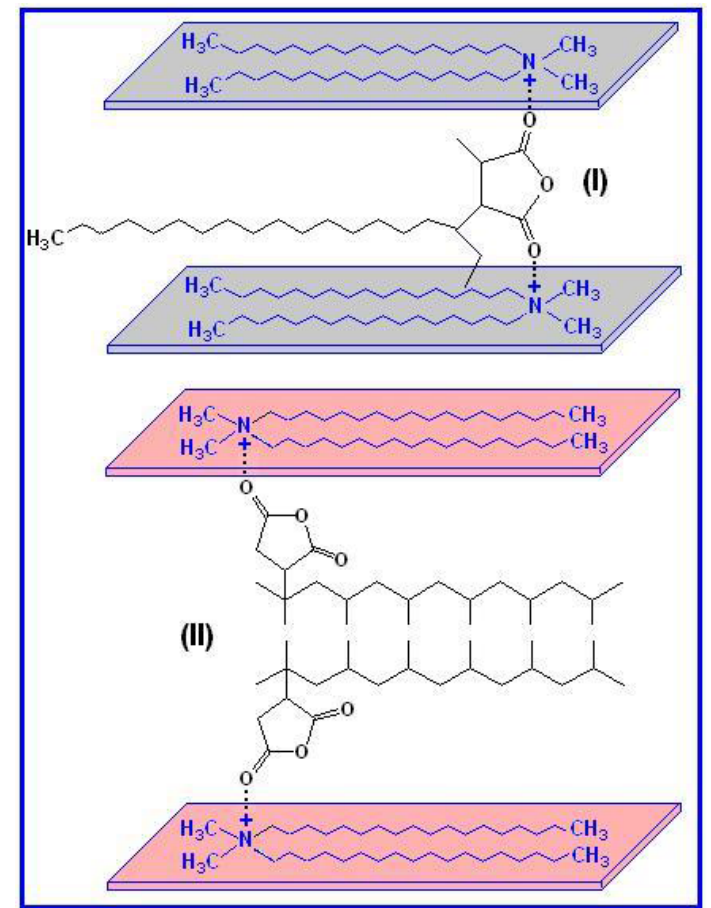

Figure 3: Physical interactions in situ processing during melt compounding of EPDM / Poly(MA-alt-1-octadecene) / PP-g-MA/ DMDA-MMT blend: intercalation through complex formation of MA units of (I) alternating copolymer and (II) graft copolymer with ammonium cation of DMDA-MMT clay.

\section{Results and Discussion}

The rubber/clay nanocomposite quality depends on the nature of organoclay particles and their contact area and force of interfacial interaction with polymer chains during melt compounding, the matrix polymer flow properties, the geometry of the mixer in the reactive extruder and the operating conditions such as temperature, mixing time and rotor speed. All these factors provide the effective in situ intercalation and exfoliation processing, which are responsive to the formation of nanostructures in rubber/organoclay nanocomposite. Taking into consideration this principle, we have utilized the following row materials-additives and nano processing methods to design and prepare a new generation of rubber/clay nanocomposites $[67,68]$.

EPDM rubber was utilized as a matrix polymer in the preparation of silicate layered nanocomposites with different compositions. Some important properties of this rubber are presented in Tables 1 and 2. Well known physical and chemical structures of montmorillonite (MMT)

\begin{tabular}{|c|c|}
\hline Properties & Values \\
\hline Specific density $(\mathrm{g} / \mathrm{cm})$ & 0.91 \\
\hline Melt Flow Index (MFI, $\left.190^{\circ} \mathrm{C} / 2.16 \mathrm{Kg}\right)(\mathrm{g} / 10 \mathrm{~min})$ & 1 \\
\hline Mooney Viscosity (at $\left.125^{\circ} \mathrm{C}, \mathrm{MU}\right)$ & 20 \\
\hline Glass-transition temperature $\left(T,{ }^{\circ} \mathrm{C}\right)$ & 1.53 \\
\hline Melting point $\left({ }^{\circ} \mathrm{C}\right)$ & 94.3 \\
\hline Degradation temperature $\left(\mathrm{T}(\max ),{ }^{\circ} \mathrm{C}\right)$ & 474 \\
\hline Content of ethylene unit (\%) & 85 \\
\hline Coontent of propylene unit (\%) & 10.1 \\
\hline Content of Ethylidenenorbornene monomer (ENB) unit (\%) & 4.9 \\
\hline
\end{tabular}

Table 1: Main properties of poly(e-co-p-co-dm) terpolymer rubber (dow chem. Co. hydrocarbon rubber nordal ip 4820) as a matrix polymer

\begin{tabular}{|c|c|c|c|}
\hline Blend & Components & Assignment & Content (wt.\%) \\
\hline & Poly(EPDM) rubber & matrix polymer & 85 \\
\hline & Poly(MA-alt-1- & compatibilizer-1 & 5 \\
\hline & octadecene) & compatibilizer-2 & 5 \\
\hline \multirow[t]{4}{*}{$\mathrm{NC}-1$} & PP-g-MA (2\%) ODA-MMT & reactive ONF-1 & 5 \\
\hline & Poly(EPDM) rubber & matrix polymer & 85 \\
\hline & Poly(MA-alt-1- & compatibilizer-1 & 5 \\
\hline & octadecene) & compatibilizer-2 & 5 \\
\hline \multirow[t]{4}{*}{$\mathrm{NC}-2$} & PP-g-MA (2\%) DMDA-MMT & non-reactive ONF-2 & 5 \\
\hline & Poly(EPDM) rubber & matrix polymer & 84.5 \\
\hline & Poly(MA-alt-1- & compatibilizer-1 & 5 \\
\hline & octadecene) & internal plasticizer & 0.5 \\
\hline \multirow[t]{7}{*}{ NC-3 } & $\alpha-H y d r o x y-\omega$-methoxy- & compatibilizer-2 & 5 \\
\hline & PEO & reactive ONF-1 & \\
\hline & PP-g-MA (2\%) & & \\
\hline & ODA-MMT & & \\
\hline & Poly(EPDM) rubber & matrix polymer & 84.5 \\
\hline & Poly[(MA-alt-1- & compatibilizer-1 & 5 \\
\hline & octadecene) & internal plasticizer & 1.5 \\
\hline \multirow[t]{7}{*}{$\mathrm{NC}-4$} & $\alpha-H y d r o x y-\omega$-methoxy- & compatibilizer-2 & 5 \\
\hline & PEO & non-reactive ONF-2 & 5 \\
\hline & PP-g-MA (2\%) & & \\
\hline & DMDA-MMT & & \\
\hline & Poly(EPDM) rubber & matrix polymer & 83.5 \\
\hline & Poly[(MA-alt-1- & compatibilizer-1 & 5 \\
\hline & octadecene) & internal plasticizer & 1.5 \\
\hline \multirow[t]{4}{*}{ NC-5 } & a-Hydroxy- $\omega$-methoxy- & compatibilizer-2 & 5 \\
\hline & PEO & non-reactive ONF-2 & 5 \\
\hline & PP-g-MA (2\%) & & \\
\hline & DMDA-MMT & & \\
\hline
\end{tabular}

Table 2: Components and composition of rubber/organoclay blends. 
Citation: Mostafa AD, Zakir MOR, Erdoğan A (2017) Preparation and Characterization of Thermoplastic Elastomers/Plasticizer - Compatibilizer/ Organoclay Nanocomposites by Reactive Extrusion System. Chem Sci J 8: 166. doi: 10.4172/2150-3494.1000166

mineral clay, organicderivatives of which are important components of the studying rubber/clay nanocomposites, were presented in Figure 4.

\section{Chemical structures of the bases additives and their nanocomposites}

Chemical structure of individual components and matrix polymer and their nanocomposites were studied by FTIR (Figures 5-7) and $\mathrm{H}$
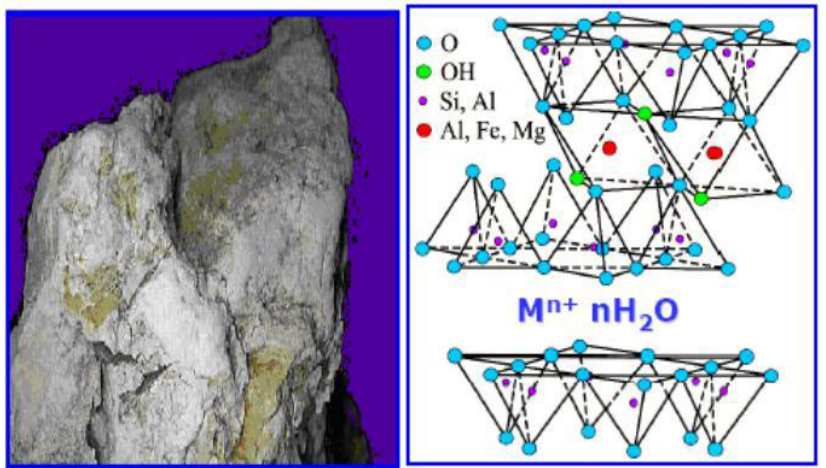

Figure 4: Montmorillonite (MMT): chemical and physical structures. Adapted from $[67,68]$.

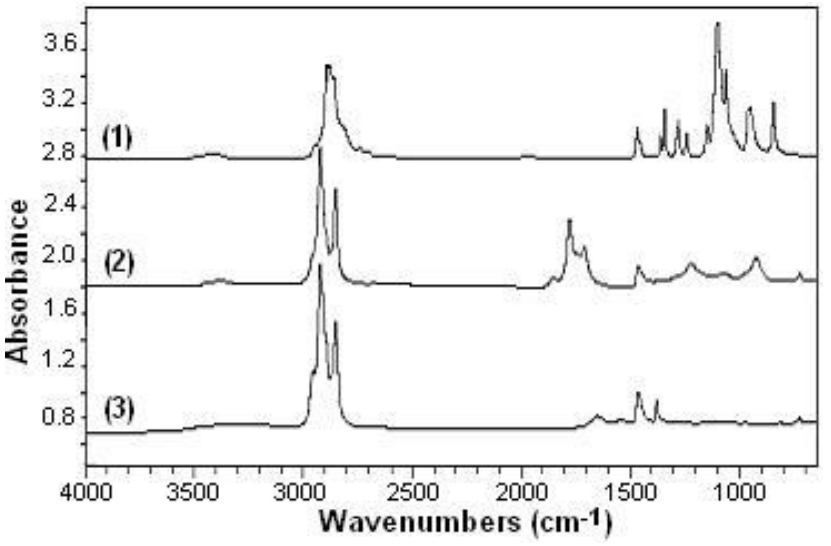

Figure 5: FTIR spectra of (1) $\mathrm{OH}-\omega-\mathrm{OCH}_{3}$-poly(ethylene oxide), (2) poly(MAalt-1-octadecene) and (3) poly(E-co-P-co-DM).

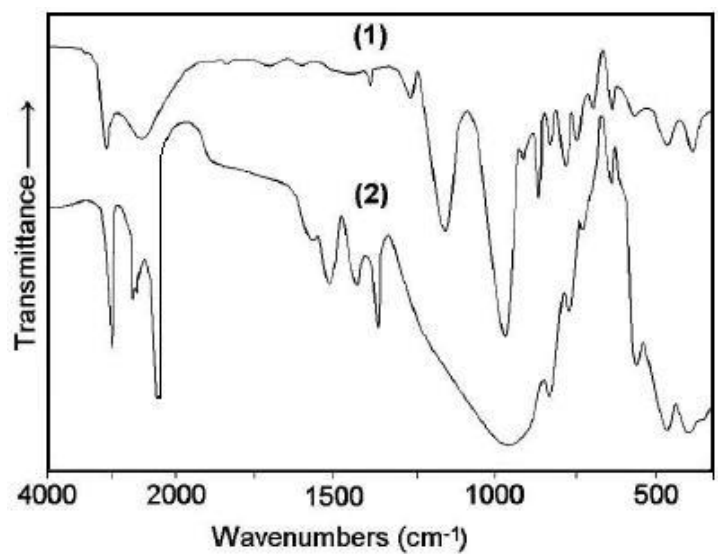

Figure 6: FTIR spectra of (1) ODA-MMT and (2) DMDA-MMT reactive and non-reactive organo-nanofillers (ONF-1 and ONF-2).

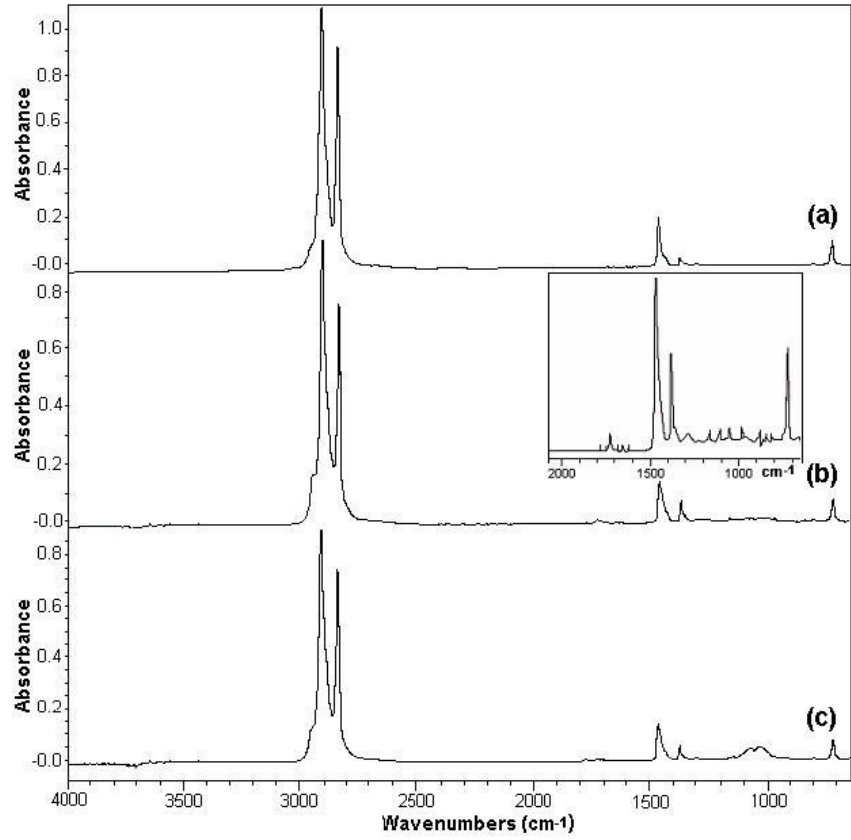

Figure 7: FTIR spectra of (a) pristinepoly(E-co-P-co-DM)and its nanocomposites: (b) poly(E-co-P-co -DM) / poly(MA-alt-1- octadecene) / PP-g-MA/ODA-MMT (NC-1) and (c) poly(E-co-P-co - DM) / poly(MA-alt-1-octadecene) / PP-g-MA / DMDA-MMT (NC-2)

$\left({ }^{13} \mathrm{C}\right)$ NMR (Figures 8 and 9) spectroscopy. The formation of amide and $\mathrm{H}$-bonded carboxyl fragments in the structures of nanocomposites were confirmed by FTIR analysis (Figure 7). Appearance of new absorption bands in the carbonyl region such as 1700,1640 and 1575 $\mathrm{cm}^{-1}$ were observed. These bands are associated with $\mathrm{C}=\mathrm{O}$ stretching in the $-\mathrm{COO}^{-}$, carboxylic (H-bonding) and amide groups, respectively. Presence of the characteristic chemical shits in NMR $\left({ }^{1} \mathrm{H}\right.$ and $\left.{ }^{13} \mathrm{C}\right)$ spectra (Figure 8) from anhydride and octadecyl units with fixed areas (or integral curves) and intensities confirmed alternating structure of copolymer.

Structure of $\alpha$-hydroxy- $\omega$-methoxy-PEO was confirmed with presence of characteristic chemical shifts in the NMR $\left({ }^{1} \mathrm{H}\right.$ and $\left.{ }^{13} \mathrm{C}\right)$ spectra (Figure 9) from protons of the side-chain $(\mathrm{CH} 2-\mathrm{O})$ n group and terminated end $\mathrm{CH} 2-\mathrm{OH}$ and $\mathrm{OCH}_{3}$ groups at 3.24, 3.42 and $3.13 \mathrm{ppm}$, and from carbon atoms of these groups at 70.2, 72.8 and $62.6 \mathrm{ppm}$, respectively.

\section{Interpretation of XRD powder diffraction analysis (physical structure)}

To evaluate the effects of organoclay nanofillers (reactive ONF-1 and non-reactive ONF-2) and dual copolymer-compatibilizers (PP-gMA and alternating anhydride-1-octadecene copolymer) natures on the in situ interfacial interactions and intercalating/exfoliating processes during melt compounding of the various PEPDM/compatibilizers/ organoclay nanofiller reactive blends, we have performed XRD patterns for the utilized individual components and their nano-composites. The results of these analyses were illustrated in Figures 10-14, and summarized in Table 3. Addition of novel functional copolymerpoly(MA-alt-1-octadecene)-compatibilizer increases the exfoliation degree and crystallinity of nanocomposites (Figure $13, \mathrm{NC}^{-1}$ and $\mathrm{NC}^{-2}$ ).

The comparative analysis of XRD spectra of matrix (a) polymer (Figure 11) and conventional graft copolymer- compatibilizer (Figure 12) 


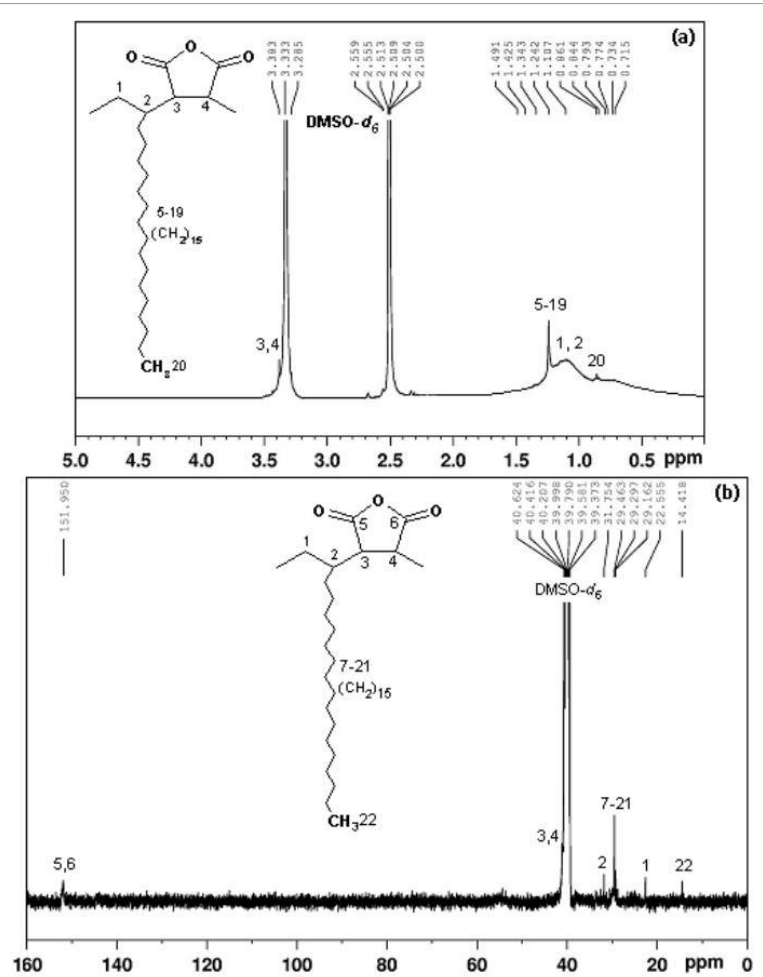

Figure 8: (a) ${ }^{1} \mathrm{H}$ NMR and (b) ${ }^{13} \mathrm{C}$ NMR spectra of poly(1-octadecene-alt-maleic anhydride) in DMSO- $d_{6}$.
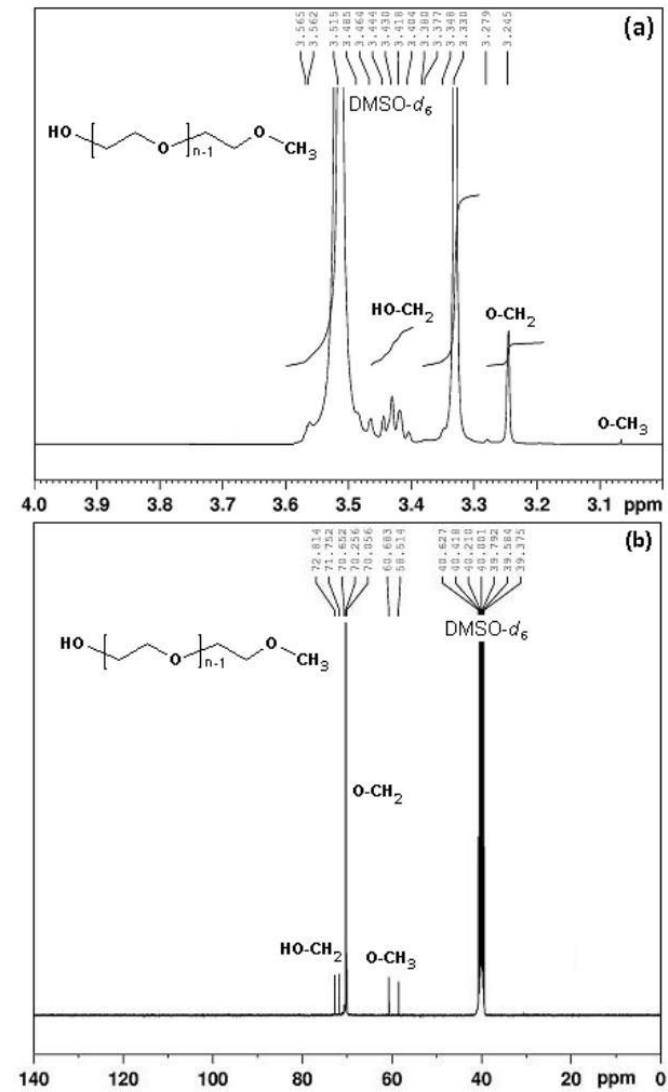

Figure 9: (a) ${ }^{1} \mathrm{H}$ NMR and (b) ${ }^{13} \mathrm{C}$ NMR spectra of $\alpha$-hydroxy- $\omega$-methoxypoly(ethylene oxide) in DMSO-d6.
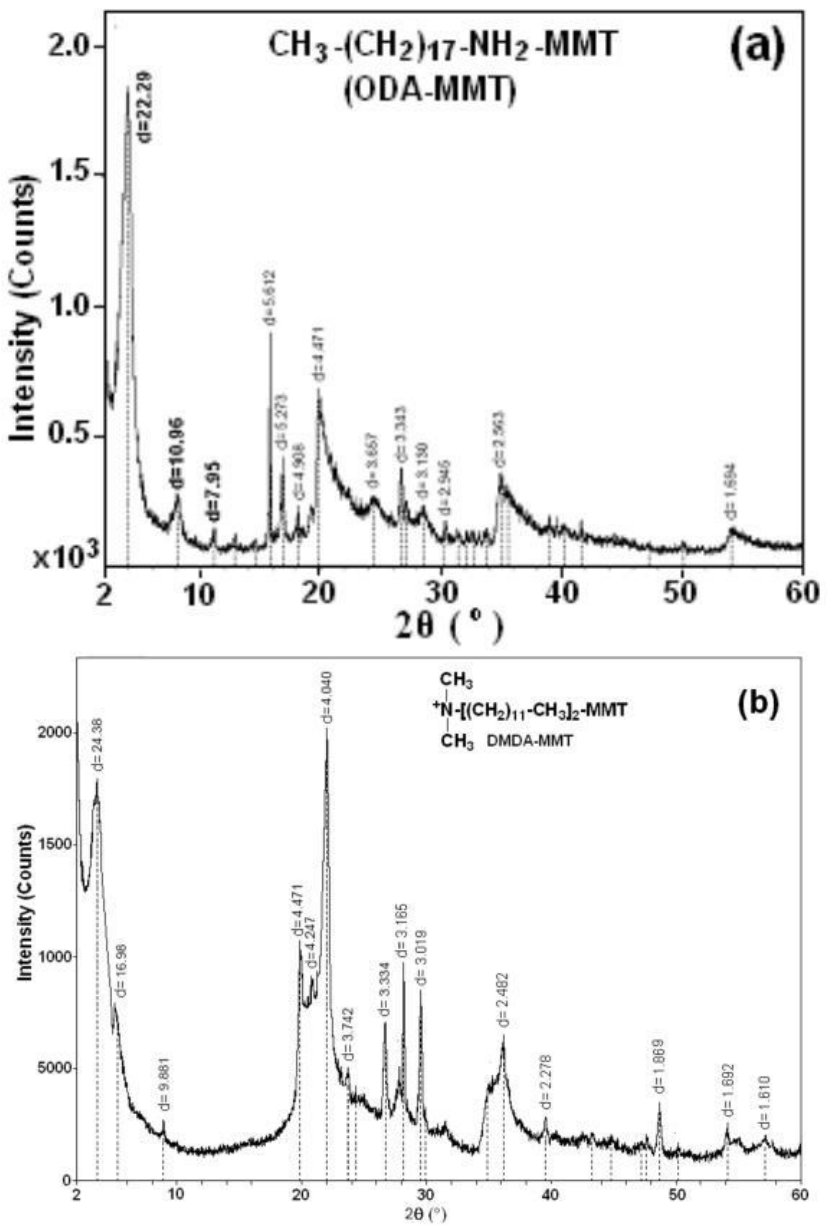

Figure 10: XRD patterns of pristine (a) ODA-MMT and (b) DMDA-MMT.

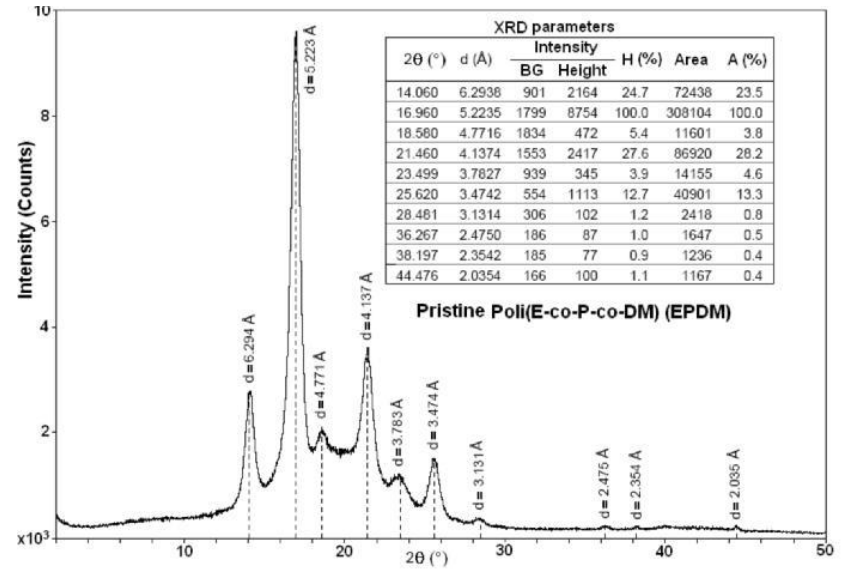

Figure 11: XRD pattern of poly(E-co-P-co-DM) terpolymer rubber.

with those for $\mathrm{NC}-1$ prepared in the presence of alternating copolymercompatibilizer and reactive organoclay (ODA-MMT) indicates a dramatic change of main crystallographic peaks in the matrix polymer pattern which transferred from multi-peak image to one relative broad peak at $2 \theta=21.5^{\circ}(\mathrm{d}$-spacing $=5.273 \AA$ ). This fact can be explained by the formation of compact crystalline structure with high exfoliation degree of the matrix polymer chains between silicate galleries. Similar effect 
Citation: Mostafa AD, Zakir MOR, Erdoğan A (2017) Preparation and Characterization of Thermoplastic Elastomers/Plasticizer - Compatibilizer/ Organoclay Nanocomposites by Reactive Extrusion System. Chem Sci J 8: 166. doi: 10.4172/2150-3494.1000166

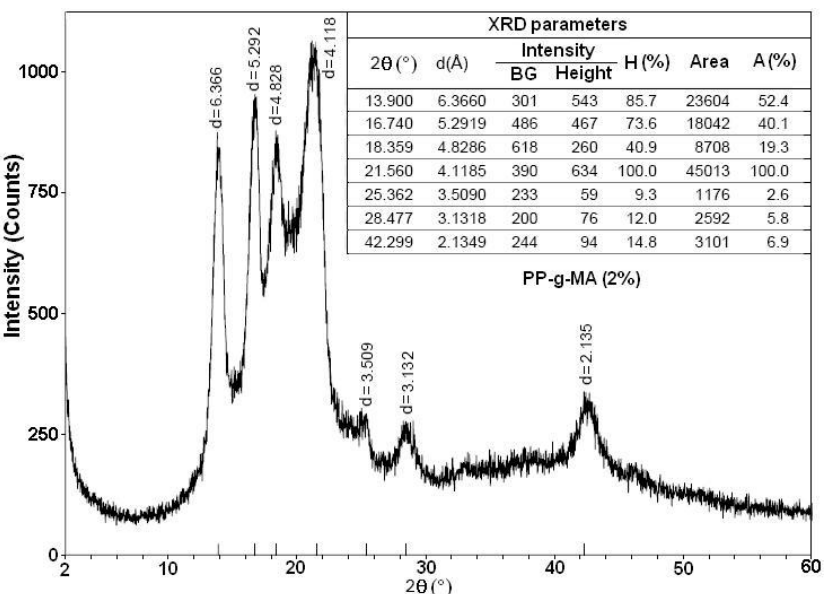

Figure 12: XRD pattern of maleic anhydride grafted PP (PP-g-MA).

(a)

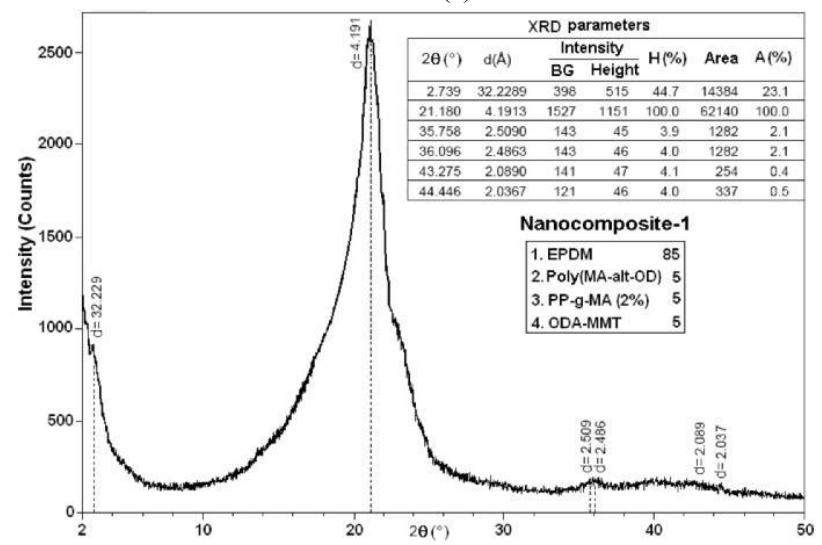

(b)

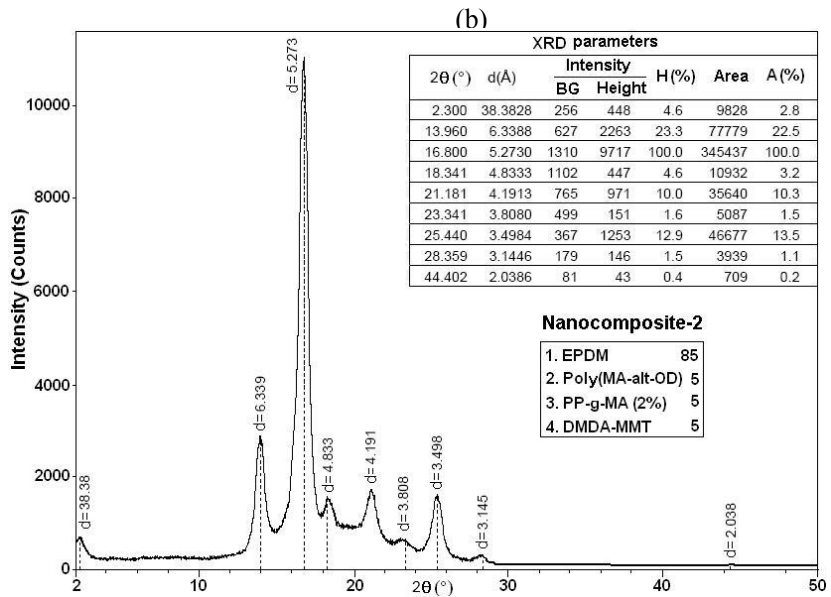

Figure 13: XRD patterns of EPDM/ODA-MMT/compatıbilizers and EPDM/ DMDA-MMT/compatibilizers nanocomposites.

with appearance of a main broad peak ( $d$ - spacing $=4.19 \AA$ (Figure $14 \mathrm{a}$, NC-3) was observed by an addition of lower amount of end hydroxylfunctionalized PEO $(\mathrm{Mn}=2000 \mathrm{~g} / \mathrm{mol})$. It can be proposed that added PEO undergoes a chemical reaction, i.e., esterification of anhydride units from dual compatibilizers, especially from alternating copolymer, and insisted on a role of internal plasticizer via formed flexibile long ester-ether side-chain branches in the melt extrusion conditions.
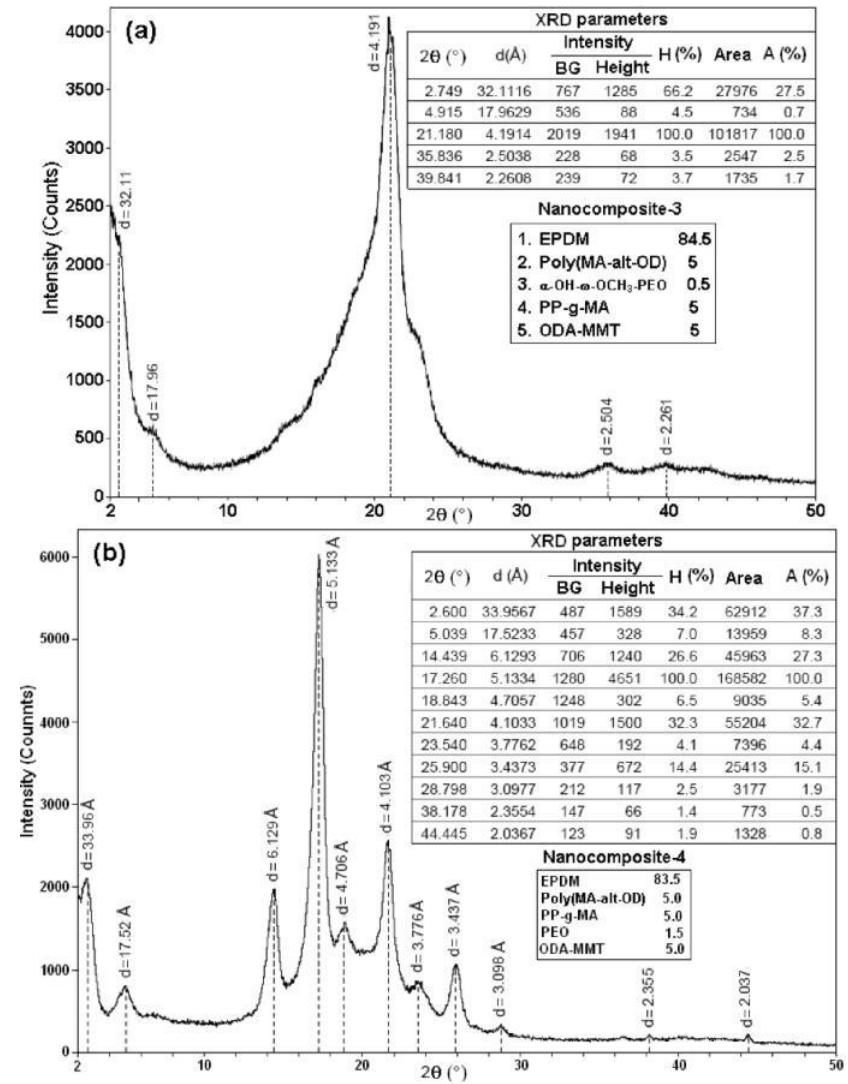

Figure 14: XDR patterns of EPDM based nanocomposites prepared with addition of (a) $0.5 \mathrm{wt} . \%$ and (b) $1.5 \mathrm{wt} \% \mathrm{a}-\mathrm{OH}-\mathrm{\omega}-\mathrm{OCH}_{3}-\mathrm{PEO}$.

\begin{tabular}{|c|c|c|c|c|}
\hline (NC)s & $\begin{array}{l}2 \theta \\
\left({ }^{\circ}\right)\end{array}$ & $\begin{array}{l}\text { d-spacing } \\
(\AA)\end{array}$ & $\begin{array}{l}\text { Intensity } \\
\text { (counts) }\end{array}$ & $\begin{array}{c}\text { ID/ED } \\
\text { (\%) }\end{array}$ \\
\hline \multirow[t]{2}{*}{$\mathrm{NC}-1$} & 2.74 & 32.23 & 913 & 33.07 \\
\hline & - & - & - & - \\
\hline \multirow[t]{2}{*}{ NC-2 } & 2.3 & 38.38 & 704 & 28.15 \\
\hline & - & - & - & - \\
\hline \multirow[t]{2}{*}{ NC-3 } & 2.75 & 32.11 & 2252 & 52.62 \\
\hline & 4.92 & 17.96 & 624 & 69.03 \\
\hline \multirow[t]{2}{*}{$\mathrm{NC}-4$} & 2.45 & 36.05 & 955 & 34.6 \\
\hline & - & - & - & - \\
\hline \multirow[t]{2}{*}{ ONF-1 } & 3.96 & 22.29 & 1848 & $25-30$ \\
\hline & 8.06 & 10.96 & 280 & \\
\hline \multirow[t]{2}{*}{ ONF-2 } & 3.62 & 24.38 & 1797 & $30-35$ \\
\hline & 5.2 & 16.98 & 740 & \\
\hline
\end{tabular}

Table 3: XRD Parameters of Poly(Epdm)/Poly(Ma-Alt-Od) Or Poly(Ma-Alt-Od)-GPeo/Pp-G-Ma/Organo-Mmt Nanocomposites.

However, in the presence of alternating copolymer-compatibilizer and non-reactive DMDA-MMT clay (Figure 13b-NC-2 ) and reactive ODAMMT clay position of all peaks is not changed but their intensities significantly increase, especially an intensity of main peak $\left(\mathrm{NC}^{-4}\right)$ increases more than 6 times after addition of PEO (1.5 wt\%).

It was observed that the almost disappearance of characteristic peaks with $d$-spacing 10.96 (1:2 silicate layers) in $\mathrm{XRD}$ patterns of $\mathrm{NC}^{-1}$ and $\mathrm{NC}^{-3}$ and their shift. To a lower region due to the $d 001$ basal reflections in all samples of the nanocomposites. These observed changes clearly indicate the significant increase of interlamellar distance $\left(\Delta d=\mathrm{d}_{\mathrm{nc}}-\mathrm{d}_{\mathrm{o}}\right)$ (Table 3) due to in situ processing through complex formation and 
Citation: Mostafa AD, Zakir MOR, Erdoğan A (2017) Preparation and Characterization of Thermoplastic Elastomers/Plasticizer - Compatibilizer/ Organoclay Nanocomposites by Reactive Extrusion System. Chem Sci J 8: 166. doi: 10.4172/2150-3494.1000166

amidization reactions between anhydride and surface alkyl amine groups, as well as increasing in crystallinity of nanocomposites as compared with pristine PEPDM matrix polymer. This can also produce a driving force necessary for the effective intercalation and exfoliation of matrix polymer chains between delaminated silicate layers. The results of comparative XRD analysis of pristine EPDM matrix polymer and its nanocomposites prepared in melt by reactive extrusion in the presence of two types of organoclays and dual polymeric compatibilizers such as conversional PP-g-MA, specific poly(MA-alt-OD) and poly(MA-alt$\mathrm{OD})$-g-PEO indicate the structural changes and improvement of the important properties of nanocomposites. The rubber macro-molecules are intercalated/exfoliated into the silicate layers of organo- MMT clays with higher values of $d$-spacing for the EPDM/organoclay systems due to the chemical (amidization and esterification in situ reactions) and physical (strong H-bonding) interactions between reactive polymer compatibilizers and alkyl amine (or ammonium cation).

\section{Nanocomposite structure-composition-thermal behavior relationships}

In this part, we have investigated the effects of structure and composition of the PEPDM matrix polymer, individual componentsadditives and their nanocomposites on the thermal parameters such as glass- transition $(\mathrm{Tg})$, melting $(\mathrm{Tm})$, crystallization $(\mathrm{Tc})$ and enthalpy of phase transitions $(\Delta \mathrm{H})$, thermal degradation and stability $(T \mathrm{~d})$, etc. These parameters were determined by thermo graphical (TGA), differential thermo graphical (DTG), differential thermal (DTA) and differential scanning calorimetric (DSC) analysis methods. Obtained results were illustrated in Figures 15-19 and summarized in Table 4.

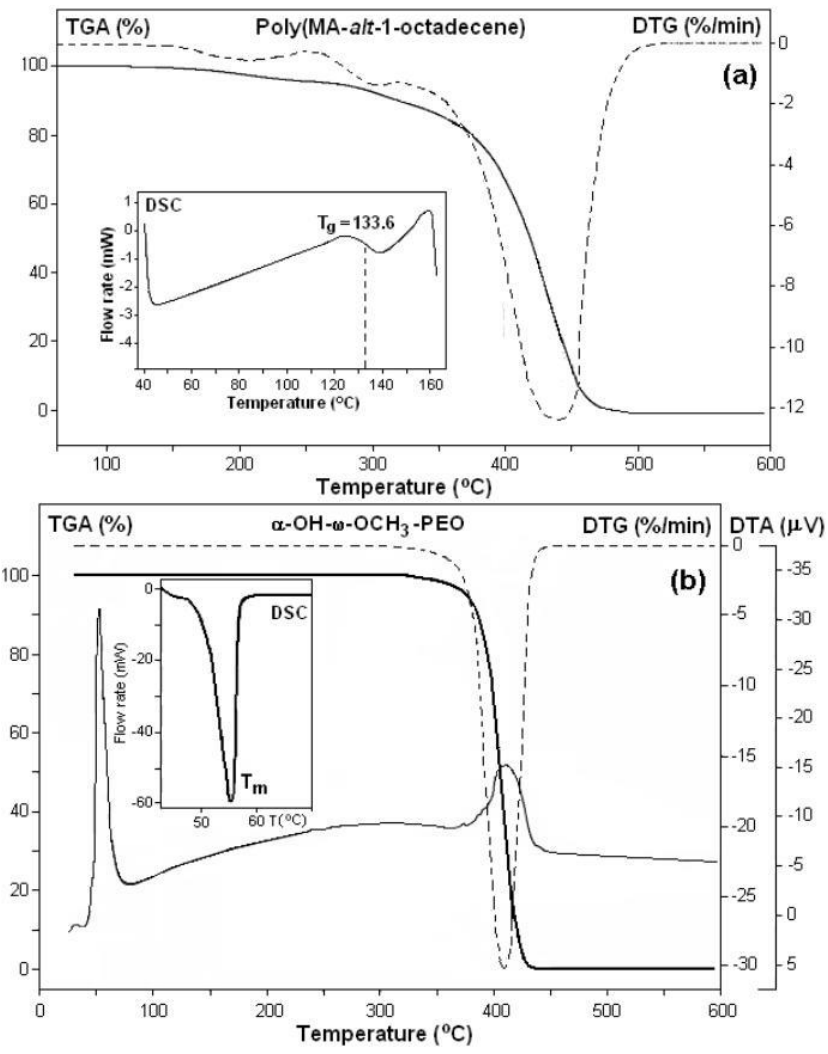

Figure 15: TGA-DTG and DSC curves of (a) alternating copolymer and $\alpha$-hydroxy- $\omega$-methoxy-poly(ethylene oxide) (PEO) as compatibilizer and internal plasticizing agent, respectively. Heating rate $10^{\circ} \mathrm{C} / \mathrm{min}$ under a nitrogen atmosphere.
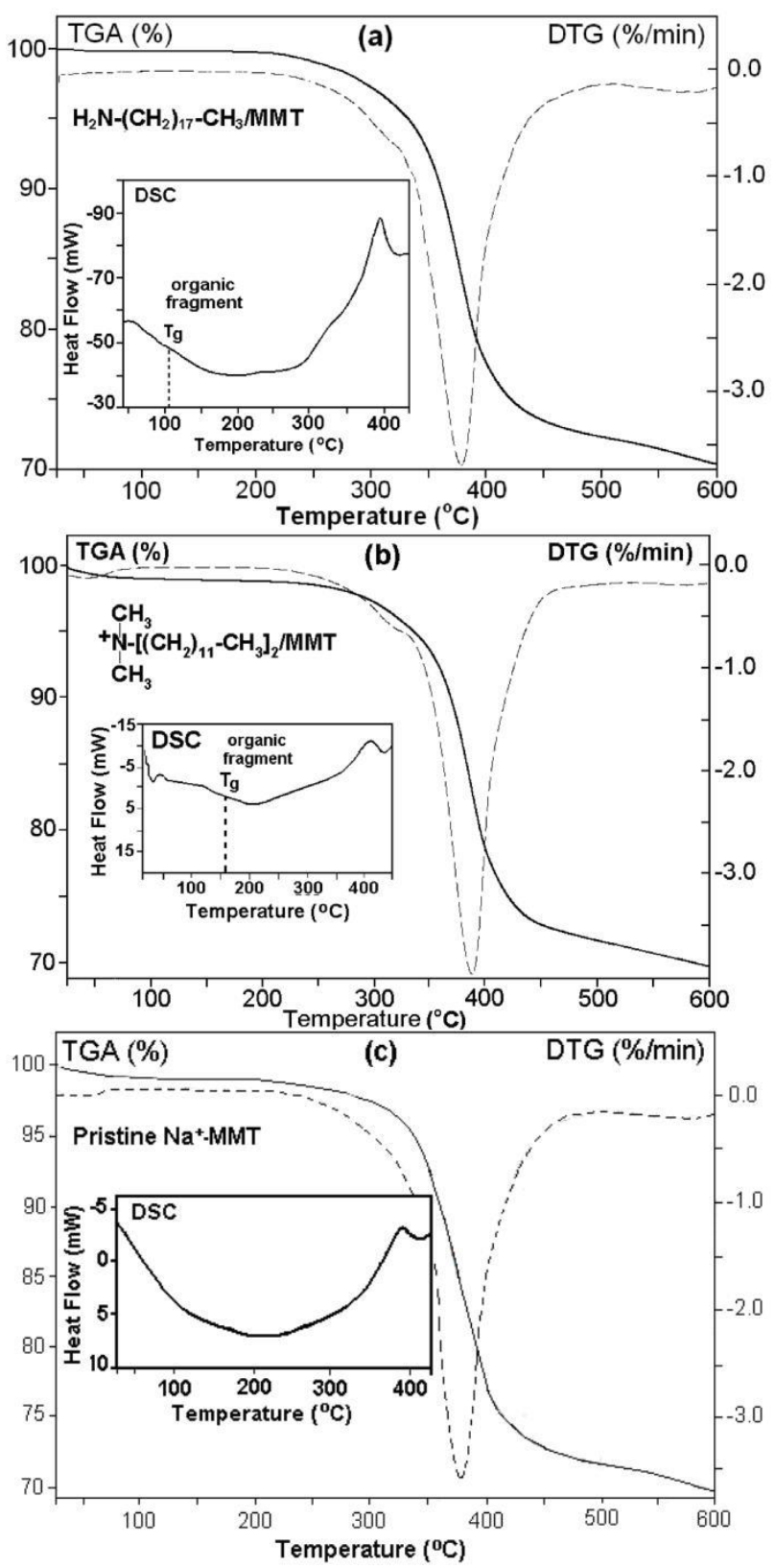

Figure 16: TGA-DTG and DSC curves of (a) reactive and (b) non-reactive organoclays, and pristine $\mathrm{Na}^{+} \mathrm{MMT}$ clay. Heating rate at $10^{\circ} \mathrm{C} / \mathrm{min}$ under a nitrogen atmosphere.

As seen from Figure 15a, alternating copolymer only exhibits glasstransition at $133^{\circ} \mathrm{C}$ and multi-steps of degradation which accompanied decarboxylation of anhydride units around $200-250^{\circ} \mathrm{C}$. While PEO $(\mathrm{Mn}=2000 \mathrm{~g} / \mathrm{mol})$ shows Figure $15 \mathrm{~b})$ melting transition is observed at $62.8 \mathrm{C}$ and relative narrow peak of chain degradation at $390^{\circ} \mathrm{C}$. Thus copolymer has a rigid- amorphous structure but PEO is a flexible crystalline polymer. Both polymers contain reactive $\mathrm{OH}$ and anhydride groups, respectively.

It was observed that in the DSC curves of both the organically modified (intercalated) MMT clays (Figure 16a and 16b) Tg-transitions appear which can be related to the transition of surface organic linkages of these clays. Broad endo-peaks are associated with the melting of 

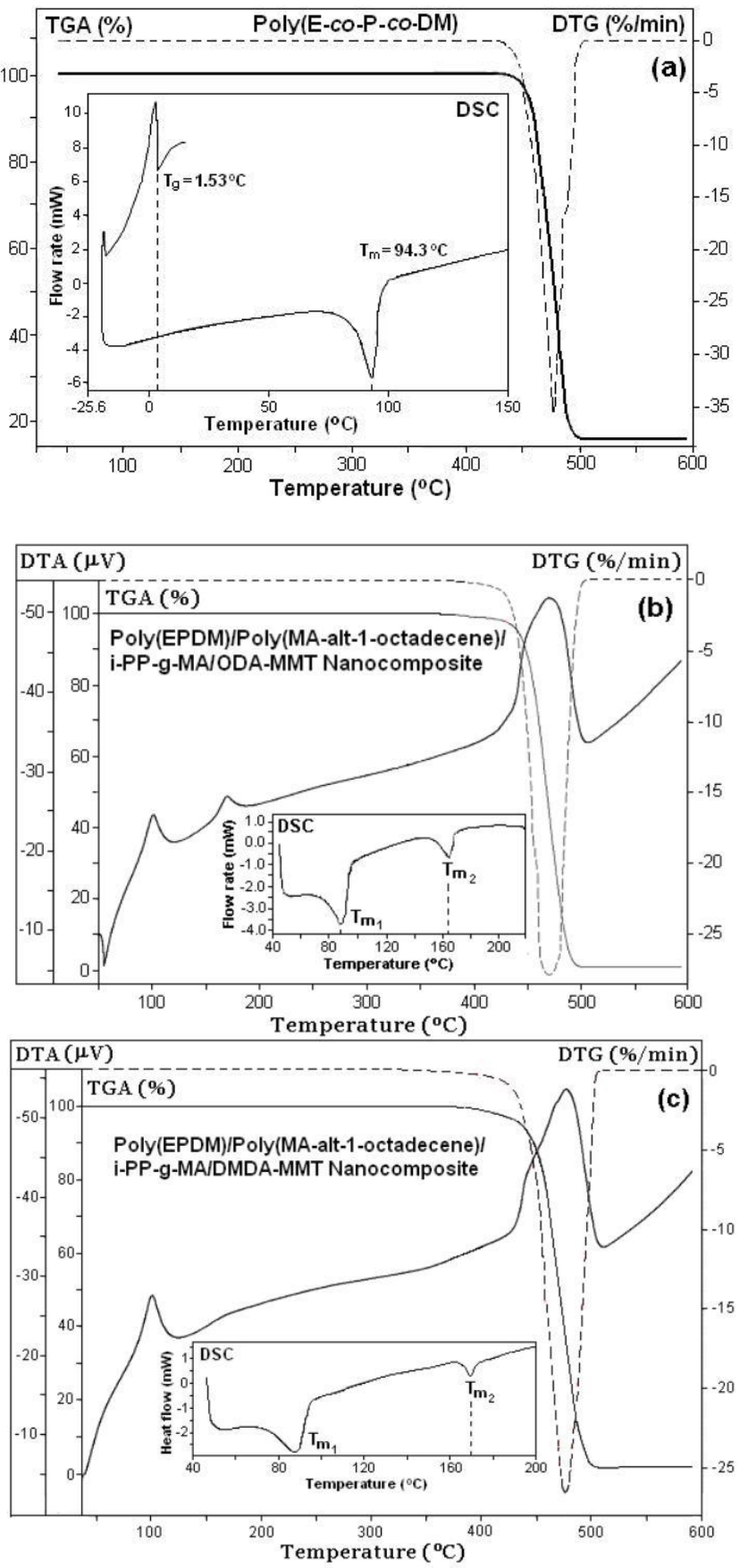

Figure 17: TGA-DTG and DSC curves of (a) pristine poly(E-co-P-co-DM) terpolymer rubber, rubber/clay nanocomposite prepared with (b) reactive (ODAMMT) and (c) non-reactive (DMDA-MMT) organoclay.

various crystalline structures (around $150-310^{\circ} \mathrm{C}$ ) of mineral clays. Pristine $\mathrm{Na}^{+}-\mathrm{MMT}$ clay does not exhibit any glass-transition, but shows very broad melting endo-peak at higher temperature region. All the MMT clays demonstrated higher thermal stability. TGA and DCS curves of PEPDM matrix polymer (Figure 17$)$ show the $\operatorname{Tg}\left(1.53^{\circ} \mathrm{C}\right)$ and $\operatorname{Tm}\left(94.3^{\circ} \mathrm{C}\right)$ transitions in the lower temperature regions similar to the other polymer elastomers. This polymer can be related to a class of synthetic rubber with semi-crystalline structure.

The results of TGA and DCS analyses of the PEPDM based nanocomposites prepared in the presence of dual compatibilizers and two types of organoclays are illustrated in Figure 18. It was found that new endo-peaks $\left(\mathrm{Tm}^{2}\right)$ appear in the DSC curves (Figures 18b and 18c) of both the nanocomposites, and characteristic $T \mathrm{~m}^{1}$ transition valuefor matrix polymer chains visibly decreases. New melting peaks at $163.9^{\circ} \mathrm{C}$ for ODA-MMT based nanocomposites and at $169.8^{\circ} \mathrm{C}$ for DMDAMMT based nanocomposites, which are associated with melting of exfoliated crystalline nanostructures, show different areas $(\Delta \mathrm{H})$, i.e., different degree of crystallinity.

This fact can be explained by the different mechanisms of nanostructure formation in both nanocomposites.

In the presence of reactive $\mathrm{ONF}^{-1}$ in situ interfacial interactions occur via chemical reactions but for nanocomposites prepared with non-reactive $\mathrm{ONF}^{-2}$ these interactions occur only via physical reactions (strong $\mathrm{H}$ - bonding).

Above mentioned proposal is confirmed by the comparative analysis of crystallization process of the pristine matrix polymer and its nanocomposites in the cooling conditions (Figure 18).

It was observed that re-crystallization of PEPDM matrix polymer proceeds rapidly $\left(\Delta=\mathrm{Tm}-\mathrm{Tc}=7.8^{\circ} \mathrm{C}\right)$ as compared with nanocomposites $\left(\Delta=\mathrm{Tm}-\mathrm{Tc}=51.8^{\circ} \mathrm{C}\right.$ for ONF-1 and $\Delta=\mathrm{Tm}-\mathrm{Tc}=65.2^{\circ} \mathrm{C}$ for NCF-2) due to higher flexibility of the rubber chains and compact crystalline structure of nanocomposites, respectively. However, crystallization temperature of PEPDM chains in both nanocomposites is almost constant.

Addition of small amount (0.5 wt\%) of end $\mathrm{OH}$ - functionalized PEO in polymer blends containing reactive dual compatibilizers and $\mathrm{ONF}^{-1}$ and $\mathrm{ONF}^{-2}$ significantly changes thermal behavior, especially melting and crystallization temperatures (Figure 19 and Table 4). It was observed as a decrease in $\mathrm{Tm}^{1}$ (matrix polymer), $\mathrm{Tm}^{2}$ (nanocomposites) values in these systems. This is a reasonable agreement which confirm the effect of PEO as internal plasticizing agent in melt reactive compounding processes via in situ chemical and physical interactions with anhydride units of used copolymer- compatibilizers.

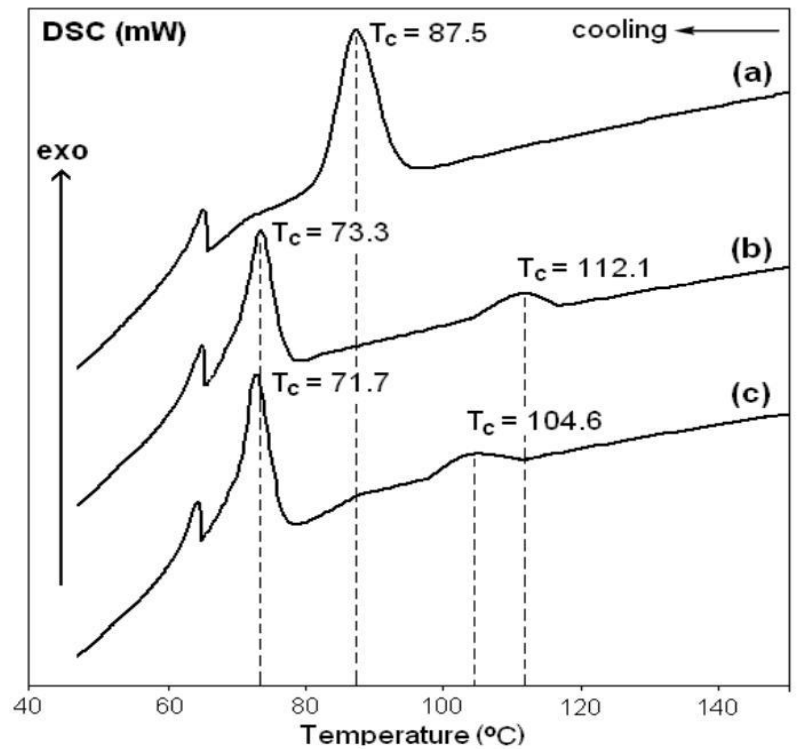

Figure 18: DSC crystallization curves of (a) pristine poly(E-co-P-co-DM) terpolymer rubber, rubber/clay nanocomposite prepared with (b) reactive (ODAMMT) and (c) non-reactive (DMDA-MMT) organoclay. 
Citation: Mostafa AD, Zakir MOR, Erdoğan A (2017) Preparation and Characterization of Thermoplastic Elastomers/Plasticizer - Compatibilizer/ Organoclay Nanocomposites by Reactive Extrusion System. Chem Sci J 8: 166. doi: 10.4172/2150-3494.1000166
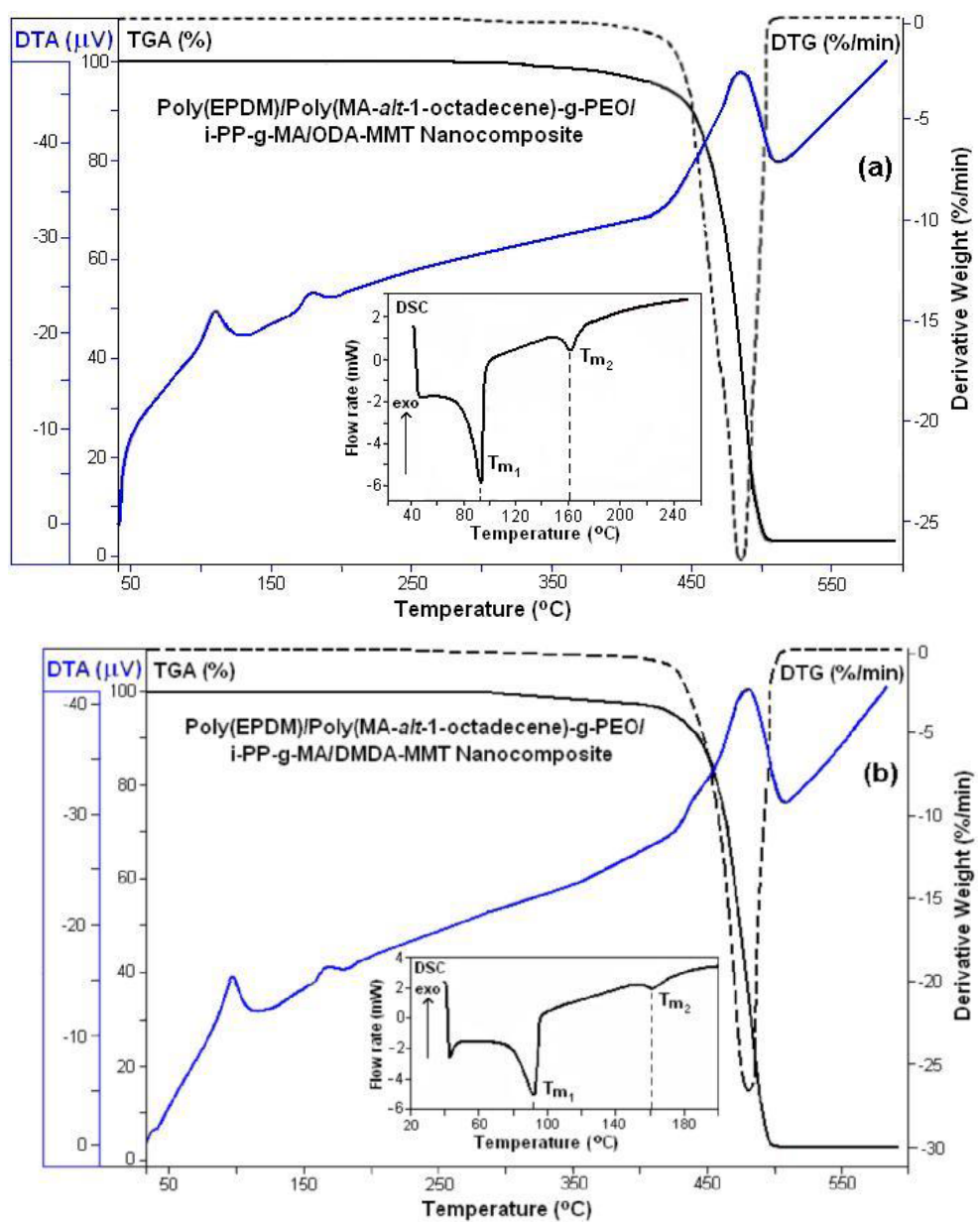

Figure 19: TGA-DTA-DTG and DSC curves of rubber/clay nanocom-posites prepared with addition of $\alpha-\mathrm{OH}-\omega-\mathrm{OCH} 3-\mathrm{PEO}$ in the presence of (a) reactive (ODAMMT) and (b) non-reactive (DMDA-MMT) organoclay.

\begin{tabular}{|c|c|c|c|c|c|}
\hline $\begin{array}{c}\text { NCs and their Individual } \\
\text { components }\end{array}$ & $\begin{array}{c}\mathbf{T m}^{-1} \\
\left.\mathbf{(}^{\circ} \mathbf{C}\right)\end{array}$ & $\left.\mathbf{\Delta} \mathbf{H m}^{-1} \mathbf{( J / g}\right)$ & $\begin{array}{c}\mathbf{T m}^{-2} \\
\left({ }^{\circ} \mathbf{C}\right)\end{array}$ & $\begin{array}{c}\mathbf{\Delta} \mathbf{H m}^{-2} \\
(\mathbf{J / g})\end{array}$ & $\mathbf{T d}\left({ }^{\circ} \mathbf{C}\right)$ \\
\hline NC-1 & 87.6 & -42.8 & 1639 & -11.83 & 473 \\
\hline NC-2 & 88.5 & -27.9 & 1698 & -467 & 476 \\
\hline NC-3 & 92.7 & -51.8 & 1623 & -3.24 & 477 \\
\hline NC-4 & 91.7 & -24.5 & 162.4 & -3.25 & 476 \\
\hline & 94.3 & & & & \\
\hline PEPDM & $\mathrm{Tg} 1.53$ & -50.5 & - & - & 476 \\
\hline & 133.6 & & & & \\
\hline Poly(MA-alt-OD & $(\mathrm{Tg})$ & - & - & - & 429 \\
\hline a, w-PEO & 61.8 & -5.7 & - & - & 399 \\
\hline
\end{tabular}

Table 4: Thermal Parameters [Melting Point (Tm), Glass-Transition (Tg) and Degradation $(\mathrm{Td}(\mathrm{Max}))]$ of Epdm Layered Silicate Nanocomposites $(\mathrm{Nc})$ and their Individual Components.

\section{Conclusion}

In summary, this work presents a new approach in the preparation of EPDM/organoclay nanocomposites which are synthesized by reactive extrusion compounding in the presence of alternating copolymer and its PEO branched derivative as novel effective compatibilizerinternal plasticizers and organoclays as reactive and non-reactive nano -fillers which are able to interact with anhydride units of functional copolymers in situ processing via amidization and strong complex formation (H-bonding) reactions. In situ processing and properties of nano- composites strongly depend on the origin of organoclays and content of compatibilizer-internal plasticizer (especially content of branched PEO linkages); rubber nanocomposites prepared in the presence of reactive ODA-MMT clay and poly(MA-alt-OD)-g-PEO exhibit relatively high performance properties. New Tm endo-peak which can be related to nanostructure and significant increase of crystallinity and thermal parameters were observed. The vulcanization of these novel nanocomposite systems by means of a conventional rubber compounding process will be a subject our future investigations in collaboration with Standard Profile Automotive Ind. \& Com. Inc. (Düzce-Turkey).

\section{References}

1. Dubois $P$, Alexandre $M$, Hindryckx $F$, Jérôme $R$ (1998) Homogeneous polyolefin-based composites. J Macromol Sci Rev Macromol Chem Phys C38: 511-565.

2. Lagaly G (1999) Introduction: from clay mineral-polymer interactions to claypolymer nanocomposites. Appl Clay Sci 15: 1-9.

3. Alexandre M, Dubois $P$ (2000) Polymer-layered silicate nanocomposites: preparation, properties and uses of a new class of materials. Mater Sci Eng R 28: 1-63.

4. Goettler LA, Lee KY, Thakkar H (2007) Layered silicate reinforced polymer nanocomposites. Polym Rev 47: 291-317.

5. Ray SS, Okamoto M (2003) Polymer/layered silicate nanocompo- sites: a review from preparation to processing. Prog Polym Sci 28: 1539-1641. 
Citation: Mostafa AD, Zakir MOR, Erdoğan A (2017) Preparation and Characterization of Thermoplastic Elastomers/Plasticizer - Compatibilizer/ Organoclay Nanocomposites by Reactive Extrusion System. Chem Sci J 8: 166. doi: 10.4172/2150-3494.1000166

6. Rzayev ZMO (2010) Polyolefin nanocomposites by reactive extrusion. CRC Press, pp. 87-127.

7. Newman ACD (1987) Chemistry of Clays and Clay Materials. Mineralogical Society Monograph, Wiley.

8. Komori Y, Kuroda K (2000) Polymer-Layered Silicate Nanocomposites. Wiley.

9. Wang MS, Pinavaia TJ (1994) Clay-polymer nanocomposites formed from acidic derivatives of montmorillonite and an epoxy resin. Chem Mater 6: 468-474.

10. Kawasumi M, Hasegawa N, Kato M, Usuki A, Okada A (1997) Preparation and mechanical properties of polypropylene-clay hybrids. Macromolecules 30: 6333-6338.

11. Okada A, Usuki A (1995) The chemistry of polymer-clay hybrids. Mater Sci Eng C3 109-115.

12. Crosby AJ, Lee JY (2007) Polymer nanocomposites: the 'nano' effect on mechanical properties. Polymer Reviews 47: 217-229.

13. Adhikari R, Michler GH (2009) Polymer nanocomposites characerization by microscopy. Polym. Rev. 49: 141-180.

14. Kornmann X, Lindberg H, Berglund LA (2001) Synthesis of epoxy-clay nanocomposites: Influence of the nature of the clay on structure. Polymer 42 $1303-1310$.

15. Messersmith PB, Giannelis EP (1995) Synthesis and barrier properties of Poly(E-Caprolactone)-layered silicate nanocomposites. J Polym Sci Part A: Polym Chem 53: 1047-1057.

16. Yano K, Usuki A, Okada A (1997) Synthesis and properties of polyimide-clay hybrid films. J Polym Sci Part A-1: Polym Chem 35: 2289-2294.

17. Lan T, Kaviratna PD, Pinnavaia TJ (1994) On the nature of polyimide-clay hybrid composites. Chem Mater 6: 573-575

18. Yeh JM, Liou SJ, Lai CY, Wu PC, Tsai TY (2001) Enhancement of corrosion Protection effect in polyaniline via the formation of polyaniline-clay nanocomposite materials. Chem Mater 13: 1131-1136.

19. Burnside SD, Giannelis EP (1995) Synthesis and properties of new poly(dimethylsiloxane) Nanocomposites. Chem Mater 7: 1597-1600.

20. Kashiwagi T, Morgan AB, Antonucci JM, Landingham MR van, Harris $\mathrm{RH}$ et al. (2003) Thermal and flammability properties of a silica-poly(methyl methacrylate) nanocomposites. J Appl Polym. Sci 89: 2072-2078.

21. Zhang JG, Wilkie CA (2003) Preparation and flammability properties of polyethylene-clay nanocomposites. Polym Degrad Stab 80: 163-169.

22. Tang Y, Hu Y, Wang SF, Gui Z, Chen Z, Fan WC (2002) Preparation and flammability of ethylene-vinyl acetate copolymer/ montmorillonite nanocomposites. Polym Degrad Stab 78: 555-559.

23. Yeh JM, Liou SJ, Lin CY, Cheng CY, Chang YW, et al. (2002) Anticorrosively enhanced PMMA-clay nanocomposite materials with quaternary alkylphosphonium salt as an intercalating agent. Chem Mater 14: 154-161.

24. Weiss (1963) Organic derivatives of mica-type layer silicates. Angew Chem Adv Int Ed 2: 134-144.

25. Gatos KG, Thomann R, Karger-Kocsis J (2004) Characteristics of ethylenepropylene-dinene monomer rubber/organoclay nanocomposites resulting from different processing conditions and formulations. Polym Int 53: 1191-1197.

26. Ma Y, Wu YP, Wang YQ, Zhang LQ (2006) Structure and properties of organoclay/EPDM nanocomposites: Influence of ethylene contents. J Appl Polym Sci 99: 914-919.

27. Ramorino G, Bignotti F, Pandini S, Ricco T (2009) Mechanical reinforement in natural rubber/organoclay nanocomposites. Comp Sci Technol 69: 1206-1211.

28. Kojima Y, Fukumori K, Usuki A, Okada A, Kurauchi T (1993) Gas permeabilities in rubber-clay hybrid. J Mater Sci Lett 12: 889-890.

29. Wang Y, Zhang L, Tang C, Yu D (2000) Preparation and characterization of rubber-clay nanocomposites. J Appl Polym Sci 78: 1879-1883.

30. Wang S, Long C, Wang X, Li Q, Qi Z (1998) Synthesis and properties of silicone rubber/organomontmorillonite hybrid nanocomposites. J Appl Polym Sci 69: 1557-1561.

31. Hakim RN, Ismail H (2009) Cure Characteristics, tensile properties and morphology of natural rubber/organoclay nanocomposites: Effect of maleated natural rubber. Polym Plast TechnolEng 48: 910-918.
32. Nasegawa H, Okamoto H, Usuki A (2004) Preparation and properties of ethylene-propylene rubber (EPR)-clay nanocomposites based on maleic anhydride-modified EPR and organophilic clay. J Appl Polym Sci 93: 758-764.

33. Coutinho FMB, Ferreira MIP (1994) Optimization of reaction conditions of bulk functionaization of EPDM rubbers with maleic anhydride. Eur Polym J 30: 911-918.

34. Datta S, Lohse DJ (1996) Polymeric Compatibilizers; Hanser: München, p 364.

35. Grigoryeva OP, Karger-Kocsis J (2000) Melt grafting of maleic anhydride onto an ethylene-propylene-diene terpolymer (EPDM). Eur Polym J 36: 1419-1420.

36. Uzuki AT, Kato M (2002) Preparation and properties of EPDM-clay hybrids Polymer 43: 2185-2192.

37. Cang YW, Yang Y, Ryu S, Nah C (2002) Preparation and properties of EEPDM organo-montmorillonite hybrid nanocomposites. Polym Int 51: 319-324.

38. Lee KY, Goettler LA (2004) Structure-property relationships in polymer blend nanocomposites. Polym Eng Sci 44: 1103-1111.

39. Ahmedi SJ, Huang Y, Li W (2005) Fabrication and physical properties of EDPM-organoclay nanocomposites. Comp Sci Technol 65: 1069-1076.

40. Yang H, Zhang X, Qu C, Li B, Zhang L, et al. (2007) Largely improved thoughness of PP/EPDM blends by adding nano-SiO2 particles. Polymer 48 : 860-869.

41. Prakashan K, Gupta AK, Maiti SN (2009) Crystallization of Polypropylene in PP/PDMS /nano-SiO2 ternary composite. Polym Plast Technol Eng 48: 775-780.

42. Yu ZZ, Ou YC, Hu GH (1998) Influence of interfacial adhesion on toughening of polyethylene-octene elastomer/nylon 6 blends. J Appl Polym Sci 69: 17111718.

43. Li QF, Kim DG, Wu DZ, Lu K, Jin RG (2001) Effect of maleic anhydride graft ratio on mechanical properties and morphology on nylon 11/ethylene-octene copolymer blends. Polym Eng Sci 41: 2155-2161.

44. Wahit MU, Hassan A, Mohd IZA, Rahmat AR, Abu BA. Morphology, thermal, and mechanical behavior of ethylene-octene copolymer toughened polyamide 6 / polypro- pylene nanocomposites. J Thermoplast Compos Mater 19: 545-567.

45. Bai SL, Wang M (2003) Plastic damage mechanisms of polypropylene/ polyamide 6/polyethylene-octene elastomer blends under cyclic tension. Polymer 44: 6537-6547.

46. Bai SL, Wan GT, Hiver JM, G'Sell C (2004) Microstructures and mechanical properties of polypropylene/polyamide 5/polvethy-lene- octene elastome blends. Polymer 45: 3063-3071.

47. Chiu HT, Chuang CY (2010) The mechanical and rheological behaviour of the PA/TPU blend with POE-g-MA modifier. J Appl Polym Sci 115: 1278-1282.

48. Wahit MU, Hassan A, Mohd IZA, Abu BA (2005) The effect of polyethyleneoctene elastomer on the morphological and mechanical properties of polyamide 6/polypropylene nanocomposites. Polym Compos 13: 795-806.

49. Wahit MU, Hassan A, Rahmat AR, Lim LW, Mohd I ZA (2006) Effect of organoclay and ethylene-octene copolymer inclusion on the morphology and mechanical properties of polyamide/polypropylene blends. J Reinforced Plast Compos 25: 933-954.

50. Hassan, Wahit MU, Chee CY (2005) Mechanical and morphological properties of PP/LLPDE/NR blends-Effects of polyoctenamer. Polym Plast Technol Eng 44: $1245-1256$.

51. Wahit MU, Hassan A, Mohd IZA, Czigány T (2009) Ethylene-octene copolyme (POE) toughened polyamide 6/polypropylene nanocomposites: Effect of POE maleation, eXPRESS. Polym Lett 3: 309-319.

52. Saelao J, Phinyocheep P (2005) Influence of styrene on grafting efficiency of maleic anhydride onto natural rubber. J Appl Polym Sci 95: 28-38.

53. Carone E Jr, Kopcak U, Gonçalves MC, Nunes SP (2000) In situ compatibilization of polyamide $6 /$ natural rubber blends with maleic anhydride. Polymer 41: 5929-5935.

54. Brosse JC, Campistron I, Derouet D, Hamdaoui AEI, Houdayer S, et al. (2000) Chemical modifications of polydiene elastomers: A survey and some recent results. J Appl Polym Sci 78: 1461-1477.

55. Mitov Z, Velichkova R (1993) Modification of styrene-isoprene block copolymers-3. Addition of maleic anhydride-mechanism. Eur Polym J 29: 597-601.

56. Amin Z, Chao L (2003) Chemical initiation mechanism of maleic anhydride 
Citation: Mostafa AD, Zakir MOR, Erdoğan A (2017) Preparation and Characterization of Thermoplastic Elastomers/Plasticizer - Compatibilizer/ Organoclay Nanocomposites by Reactive Extrusion System. Chem Sci J 8: 166. doi: 10.4172/2150-3494.1000166

grafted onto styrene-butadiene-styrene block copolymer. Eur Polym J 39: 1291-1295.

57. Jia D, Luo Y, Li Y, Lu H, Fu W, et al. (2000) Synthesis and characterization of solid -phase graft copolymer of polypropylene with styrene and maleic anhydride. J Appl Polym Sci 78: 2482-2487.

58. Nakason C, Kaesman A, Homsin S, Kiatkamjornwong S (2001) Rheological and curing behavior of reactive blending. I. Maleated natural rubber-cassava starch. J Appl Polym Sci 81: 2803-2813.

59. Sclavons M, Carlier V, Roover BD, Franquinet P, Devaux J, et al. (1996) The anhydride content of some commercial PP-g-MA: FTIR and titration. J Appl Polym Sci 62: 1205-1210.

60. Oostenbrink J, Gaymans RJ (1992) Maleic anhydride grafting on EPDM rubber in the melt. Polymer 33: 3086-3088.

61. Coutinho FMB, Ferreira MIP (1994) Characterization of EPDM rubber modified with maleic anhydride (MAH) by diffuse reflectance FTIR (DRIFT). Polym Test 13: $25-34$
62. Hakim RN, Ismail H (2009) Cure characteristics, tensile properties and morphology of natural rubber/organoclay nanocomposites: Effect of maleated natural rubber. Polym Plast Technol Eng 48: 910-918.

63. Ismail H, Hakim $\mathrm{R}$ (2008) Organoclay filled natural rubber nanocomposites: The effect of filler loading and mixing method. J Reinforced Plast Comp 27: 1909-1924.

64. Ismail $\mathrm{H}$, Chia $\mathrm{HH}$ (1998) The effects of multifunctional additive and epoxidation in silica filled natural rubber compounds. Polym Test 17: 199-210.

65. Ismail H, Chia HH (1998) The effects of multifunctional additive and vulcanization systems on silica filled natural rubber compounds. Eur Polym J 34: 1857-1863.

66. Varghese S, Kocsis JK, Gatos KG (2003) Melt compounded epoxidized natura rubber/layered silicate nanocomposites: structure-properties relationships. Polymer 44: 3977-3983.

67. Hendricks SB (1941) Base exchange of the clay mineral mont- morillonite for organic cations and its dependence upon absorption due to Wander-Waals forces. J Phys Chem 45: 65-81. 